\title{
Geografía del folclore del Noroeste Argentino: una música entre el hombre y la tierra. El caso de la Quebrada de Humahuaca ${ }^{1}$
}

\author{
Sarah MiLLIARD \\ Master en «Géographie de l’Environnement et du Paysage», Universsité Toulouse-Le Mirail (Francia) \\ milliardsah@hotmail.com
}

Recibido: 26 de agosto de 2011

Aceptado: 28 de septiembre de 2011

\section{RESUMEN}

El folclore del noroeste argentino se caracteriza por ser a la vez actor y revelador de múltiples relaciones geográficas, tanto a nivel concreto y cartografiable como simbólico. Las practicas musicales de la Quebrada de Humahuaca, actualmente en plena revalorización, siguen manteniendo una fuerte raíz cultural andina en cuanto a las representaciones de la relación entre naturaleza y cultura. En el actual contexto argentino de trabajo sobre su memoria nacional, de reintegración de patrimonios indígenas y de circulación de ideas y gente entre la Argentina «moderna» y «europea» y la región andina, el objetivo de esta investigación es comprender los sistemas tangibles y simbólicos de la relación entre naturaleza y cultura articulados por la música, para estudiar después la hipótesis de una transmisión cultural de las relaciones con la naturaleza que responda a una necesidad de nuevos valores medioambientales.

Palabras clave: Argentina, Quebrada de Humahuaca, folclore, territorio, paisaje, patrimonio inmaterial, geografía de la música.

\section{Geography of Northwest Argentinian Folklore: A Music between Man and Earth. The Case of Quebrada de Humahuaca}

\begin{abstract}
The Norwest Argentinean folk music is at the same time acting and revealing multiple geographic relationships, both concrete and symbolic. The musical practices of the Quebrada de Humahuaca, now in full revalorization, continue to maintain a strong Andean cultural roots respecting to the representations of the relationship between nature and culture. In the actual Argentinian context of integration of the native cultural heritages and circulation of ideas and people between the «European» Argentina and the Andean region, the objective of this research is to understand the tangible and symbolic systems of the relationship between nature and culture articulated by the music, to then explore the cultural transmission hypothesis of relationships with nature that responds to a need for new environmental values.
\end{abstract}

Key words: Argentina, Quebrada de Humahuaca, folklore, territory, landscape, intangible heritage, geography of music.

Sumario: 1. Introducción. 2. Naturaleza y cultura en el folclore de la Quebrada de Humahuaca: perspectivas geográficas. 3. Las fiestas «indias» entre música y tierra. 4. Análisis referencial de letras de canciones: una conciencia geográfica. 5. Consideraciones finales. 6. Referencias bibliográficas.

1 El presente trabajo resulta de la investigación Musiques populaires, environnement et paysage. Ancrage et circulation de savoirs sur la terre. Le cas du folk-lore du Nord-Ouest argentin ou la Pachamama à Buenos Aires (Milliard 2010), memoria de fin del master «Géographie de l'Environnement et du Paysage» (GEODE 2009-2010) de la Université Toulouse-Le Mirail. 
«La experiencia muestra que una firme dosis de empirismo, un poco de humildad y mucha paciencia e intuición son, muy a menudo, los únicos requisitos para dar cuenta con fineza de los usos y costumbres de los demás» (Descola 2011: 55).

\section{Introducción}

Si bien la relación entre hombre y naturaleza ha sido tradicionalmente competencia de la antropología, está ya admitido que es imprescindible un diálogo interdisciplinario para una mejor comprensión de la complejidad de la cuestión. Desde las perspectivas de la geografía social y cultural y a partir de una larga estadía en los Andes del Noroeste Argentino (NOA en lo sucesivo), presentaremos aquí una geografía de las músicas ${ }^{2}$ del NOA enfocada en sus interrelaciones con la tierra, entendida ésta como noción geográfica (territorio, paisaje, medio ambiente). El interés de tal estudio radica en que el contexto actual de la Quebrada de Humahuaca (provincia de Jujuy), donde enfocamos nuestra investigación, es el de una transición muy notable en cuanto a la representaciones dominantes de la sociedad argentina: está pasando de la marginalización geográfica y del desprecio cultural, a la valorización patrimonial de su identidad indígena ${ }^{3}$. Dentro de este contexto, las prácticas musicales parecen ser no sólo un medio de expresión de las poblaciones nativas en cuanto a su relación con la tierra, sino también una oportunidad de encuentro privilegiado entre los nativos del pueblo y sus nuevos habitantes, procedentes de otros ámbitos culturales en lo que se refiere a las representaciones de la naturaleza.

Adoptando una visión crítica y reflexiva de las denominaciones («tradición», «indio», «folclore»), prestaremos atención a las categorías de análisis para estudiar en qué medida las músicas del NOA expresan una geografía andina, cómo parecen conllevar saberes locales sobre la relación con la naturaleza, y cómo dichos saberes parecen transmitirse y servir de referente para fomentar «nuevos» valores respecto al medio ambiente y al paisaje (Figura 1).

2 La geografía de la música es un campo de la geografía social y cultural desarrollado a partir de la década de 1970 en los EE.UU. y en Francia. V.gr. los trabajos de Raibaud (2009), Guiu (2007) o Leroux (2007), como exponentes de las últimas propuestas teórico-metodológicas de esta área de conocimiento.

3 La Quebrada de Humahuaca fue declarada Patrimonio de la Humanidad en 2003 por la UNESCO en la categoría «paisaje natural y cultural». Si bien es cierto que esta clasificación ha iniciado muchos y fuertes cambios a nivel socioeconómico y seguramente ha impulsado el turismo. La instalación de una población «gringa»calificada como hippie empezó anteriormente, y no es consecuencia de esta clasificación. 


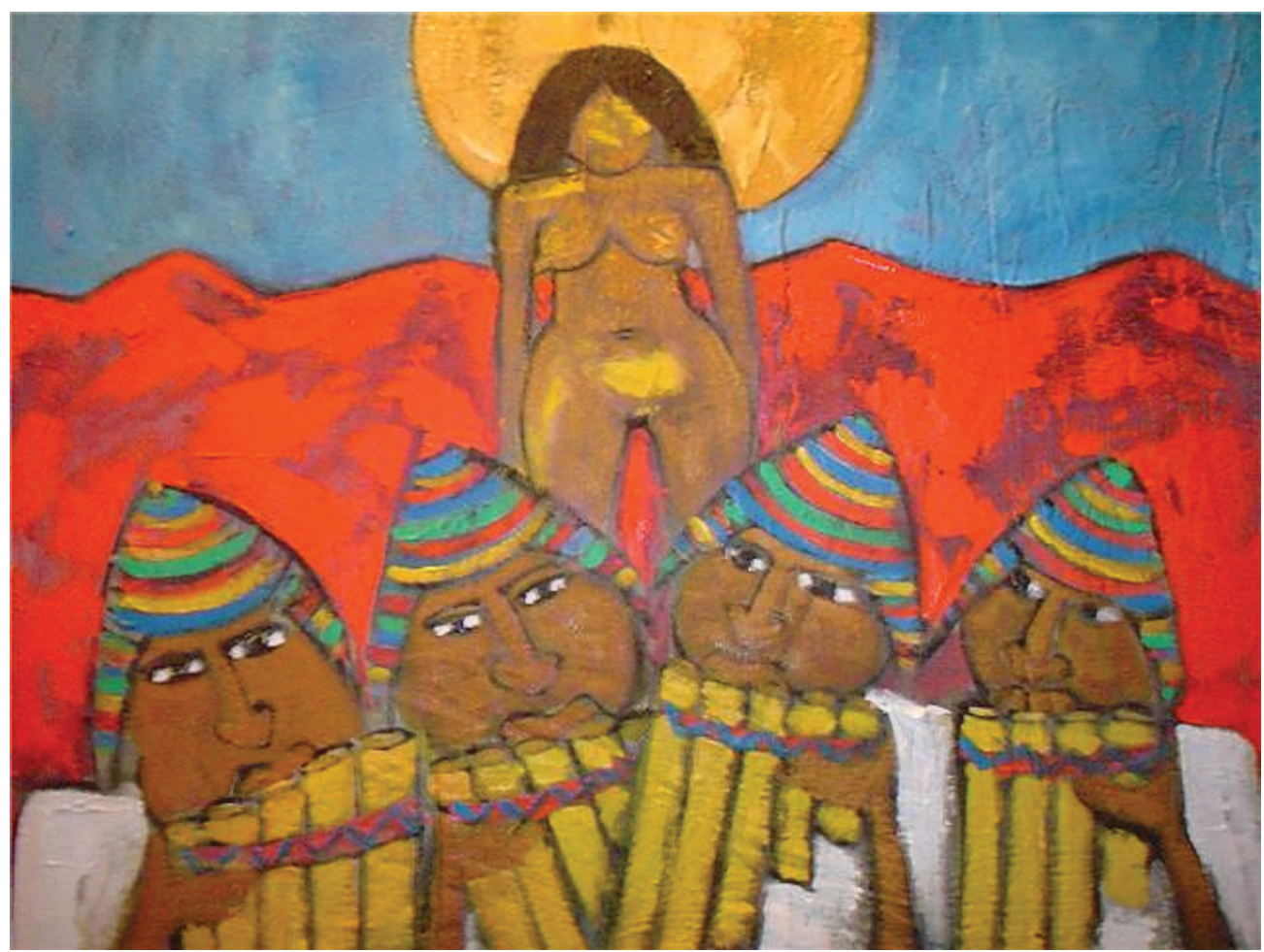

Figura 1: Pintura de Haro Galli, artista salteño radicado en la Quebrada de Humahuaca, representando a la Pachamama detrás de unos músicos andinos.

\section{Naturaleza y cultura en el folclore de la Quebrada de Humahuaca: perspectivas geográficas}

Inspirada por las posturas epistemológicas de la geografía cultural del paisaje (Berque 2007; Dardel 1952) y la antropología de la naturaleza (Descola 2011), nuestra hipótesis de trabajo considera las músicas folclóricas del NOA como una traducción de la relación con la tierra de los habitantes de la Quebrada de Humahuaca, así como geoindicadores de comportamientos y representaciones sociales.

Aunque situar con detalle nuestra investigación en su contexto científico y geográfico es muy pertinente (Milliard 2010), para enfocar concisamente la temática precisa de este dossier sólo comentaré muy brevemente, a modo de prólogo, dos interrogantes fundamentales. Primeramente es necesario contestar al cómo y el porqué la geografía se interesa en la relación entre naturaleza y cultura. Frente a la crisis social y ambiental, la geografía - junto con las ciencias sociales- atraviesa un profundo cambio de paradigma y empieza a cuestionar la jerarquía y los valores tradicionalmente asentados en el mundo occidental moderno (la «ontología naturalista» según la tipología de Descola 2005). Entramos en un pensamiento dialéctico de la relación 
hombre/tierra, tratando de considerar las interrelaciones y correspondencias tanto a nivel físico y material, como a nivel sensible, simbólico y ontológico. La historia de la geografía humana y cultural (Berque 2007; Dardel 1952; Frémont 1974) nos lleva a considerar una relación dialéctica y dinámica entre la naturaleza y la cultura, «separadas» por fronteras finalmente muy porosas y en constantes y múltiples interacciones. Este proceso lleva también a una nueva mirada sobre las culturas «no modernas» o «no naturalistas» ${ }^{4}$ (evolucionando desde la institucionalización de la «geografía tropical» por Pierre Gourou [Bruneau 2000]), queriendo entender otra manera de relacionarse con el espacio y sus elementos e identificar nociones y conceptos de una geografía «india» (Lézy 2000).

Asimismo, la segunda cuestión a resolver será la de en qué medida el llamado folclore del NOA interpretado en la Quebrada de Humahuaca se vincula con esta cuestión. La particularidad de nuestro terreno es que se trata de una región andina «periférica», extremadamente marginada por la nación Argentina hasta una época muy reciente, y situada en una dinámica entre arraigamiento y circulación, tradición

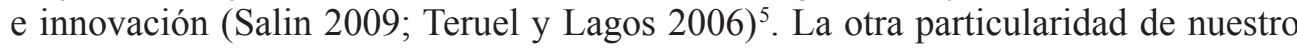
estudio reside en el hecho de abordar prácticas culturales tales como la música desde el punto de vista de la geografía. Remitiremos aquí a la presentación detallada del folclore del NOA que hicimos en un trabajo anterior (Milliard 2010), especificando tan sólo que el folclore de la Quebrada de Humahuaca, constituido por diversos legados musicales ${ }^{6}$, tiene múltiples relaciones geográficas -territorialización, arraigamiento y

4 ¿Donde termina la naturaleza, donde empieza la cultura? Así plantea el problema P. Descola, antropólogo familiar de los geógrafos y seguramente uno de los pensadores más avanzado en esta temática. A partir de Pardelà nature et culture (2005), Descola expone que si la distinción entre naturaleza y cultura sólo se encuentra en el mundo occidental moderno, por todas parte del mundo se establece una distinción entre la interioridad (lo invisible: la conciencia, el alma manifestándose por sus efectos) y la fisicalidad (todo dispositivo material incluso el cuerpo). Dentro de su tipología organizada en cuatro ontologías, las culturas andinas tienen una ontología analógica de un mundo compuesto por una proliferación de seres distintos pero interconectados por una red de correspondencias. De esta reflexión nace el proyecto de fundar una "antropología simétrica» (Descola 2005: 68, a partir de Bruno Latour) que «sitúa a los Modernos (naturalista) y los No Modernos (todas las otras ontologías) sobre un mismo plano», y propone considerarlos de igual a igual porque «no son las facultades que distinguen los cazadores-recolectores de los eruditos, sino los esquemas de codificación y de discriminación de la realidad fenomenal por los cuales aprendieron a exponer y transmitir su experiencias de las cosas» (Descola 2005: 66).

5 A este respecto, y para el desarrollo del concepto de «le retour du refoulé» en el contexto sociocultural de la Argentina contemporánea, cfr. el trabajo de Bernand 2007.

6 El folclore de la Quebrada de Humahuaca se caracteriza por pertenecer tanto al grupo grande del folclore del NOA (ritmos de zambas, chacarera, gato, huella, etc.) cercano a las regiones de monte y llanura más criolla (Santiago del Estero, parte de Tucumán), como al folclore claramente andino (huayno, bailecitos, carnavalitos, coplas, bagualas cuecas, sayas, takiraris). Podemos diferenciar tres «espacios musicales» (ámbito musical producido por una cultura en relación con un medio geográfico y social dado, según Plisson 1987: 222) en este folclore de la Quebrada. En primer lugar, el espacio de los pueblos agropastoriles tejedores y ceramistas de los altos valles andinos, como los valles Calchaquíes (Tucumán y Salta), o la Quebrada de Humahuaca. Es un espacio musical tritónico. En segundo lugar, el espacio de las culturas precolombinas dominantes que tuvieron una gran influencia desde Colombia hasta el norte argentino (Inca, Mochica y Chimú), difundiendo generalmente una escala de sonidos pentatónicos. Esta influencia está sobre todo presente en la parte norte del NOA (Jujuy y parte de Salta) mezclada con lo tritónico. Por último, en tercer lugar, el espacio musical colonial constituido de un conjunto complejo de músicas europeas y prehispánicas, siguiendo dos grandes ramas: una con dominante prehispánica con danzas colectivas procedente de Bolivia, de la puna y de la Quebrada de Humahuaca (huaynos, carnavalitos, sikureada, etc.), y la otra con dominante europeo con danzas de pareja 
circulación espacio-temporal y socio-cultural-, incluyendo la de ser una traducción (sensu Berque 2007) de las percepciones y representaciones actuales de la relación entre el hombre y la naturaleza en esa parte del mundo andino. Aquí presentaremos nuestra hipótesis y primeros avances de investigación obtenidos a partir del apoyo teórico y metodológico de la geografía de la música y de la investigación del género folclore en Argentina.

Nos interesaremos entonces en la dimensión geográfica inmaterial, considerando las músicas como expresión de una relación con el paisaje, preguntando si en éstas «la naturaleza es traducida en términos de culturas (...), siempre presente» y aún «activada y actualizada» (Berque 2007). De acuerdo con Gudemos (2008), proponemos estudiar estas músicas como traducción de un modo sensible y activo de conocimiento de la relación con la naturaleza y el paisaje, como una especie de «gestos de la naturaleza» caracterizando históricamente ciertas prácticas musicales del mundo andino.

Para ello presentaremos las diferentes y principales formas en que las músicas invierten el espacio de la Quebrada de Humahuaca (lugares, momentos, tipos de músicas, instrumentos, actores) y los métodos considerados para estudiarlas.

\section{Las fiestas «indias» entre música y tierra}

A fin de poder resolver esta cuestión, distingamos primero algunas de las prácticas musicales asociadas a fiestas relacionadas con la tierra y revestidas de cierto carácter ritual propio de la cultura andina local. Nuestra intención en el futuro y en lo que ya estamos trabajando actualmente (Milliard 2010), es poder organizar todas estas prácticas a partir de una metodología que permita hacer mapas de las relaciones territoriales (incluyendo las representaciones) y, a través de entrevistas, analizar e interpretar el sentido que estas fiestas tienen para sus practicantes. Asimismo, sería muy interesante prestar atención particular a las percepciones y al discurso de los que las practican sin ser nativos, para entender cómo y por qué llegaron a adoptar un rito por elección propia y no por una tradición heredada.

\subsection{El carnaval}

El carnaval se festeja en todos los pueblos de la Quebrada durante nueve días del mes de febrero. Es un ejemplo de sincretismo que sigue viviendo dentro de formas heredadas de la colonización. Así, Losada (2005: 52) señala cómo

«varios autores señalan que antes de la llegada del carnaval europeo caracterizado como pagano, medieval y popular, se celebraba en esta zona el Qhapaj Raimi, y aun-

(gato, chacarera, zamba, cueca, etc). En este sentido, diferentes autores insisten en la complejidad del origen y de la evolución geográfica y cultural, resolviendo que la música folclórica del NOA es un genero de alcance panandino que representa un conglomerado de elementos musicales procedentes de diferentes regiones de los Andes, y marcado asimismo por la presencia de componentes europeos en cuanto a la instrumentalización y los arreglos; por esta razón sería necesario tender a alcanzar una visión general del proceso histórico de transformación de lo tradicional en folclórico. 
que la política de la conquista fue extirpar sistemáticamente las «idolatrías», se puede encontrar referencias a estas antiguas celebraciones de la época de la cosecha del carnaval actual. Esto es evidente tanto por el lugar que ocupa el carnaval en el calendario festivo-ritual, como por las características propias de su ritual: una serie de actos alrededor de los mojones que rinden homenaje a la pachamama -darle de comer y de beber, zaumarla- y coincidiendo con la época de cosecha del maíz y la estación lluviosa».

El carnaval se considera como un rito comunitario que celebra la abundancia, la fertilidad y la reproducción. La música es indisociable de esta celebración: durante las ofrendas a la pachamama, las comparsas, tocando sus tarkas (flauta panandina vertical y tallada en una sola pieza de madera), invitan a la danza para iniciar la celebración del ciclo agrícola... aunque hoy en día esta invitación corre a cargo de bandas de metal y a ritmo de cumbia, una música más moderna.

Durante todo el carnaval, y a lo largo del día, las comparsas, muy numerosas en todas las localidades, van por las calles de los pueblos entonando ritmos de carnavalitos - entre otroscon todos sus seguidores carnavaleros. Su trayecto esta organizado en el espacio, sigue las diferentes invitaciones hechas por las diferentes casas que ese año pudieran convidar a su comparsa a acompañar los pagos realizados a su mojón o lugar específico para las ofrendas.

Otras manifestaciones musicales típicas del carnaval, aunque también se tocan en otras ocasiones, son las coplas ${ }^{7}$. Los copleros -mayoritariamente mujeres-, son en general personas nativas ya adultas o ancianas que entonan rondas de coplas que son, en el contexto de la Quebrada, un canto tritónico acompañado por la caja. «Las principales actividades de los copleros o copleras son vinculadas al trabajo de la tierra, la crianza de animales, la artesanía tradicional de tejido y cerámica (...) y mantienen una relación directa y fluida con la Pachamama» (Mennelli 2007: 48). Estas características culturales se reencuentran en su canto: «ahicito ahicito, la flor del maicito», por ejemplo, un refrán derivado de una copla popular y anónima.

El carnaval es un ejemplo significativo del vínculo que la música tiene con la tierra: territorializan el espacio al efectuar sus trayectos pasando por sitios bien definidos y por lo tanto cartografiables, transformando toda la Quebrada en un estupendo paisaje sonoro. Durante nueve días se escucha el carnaval por todas partes y en cada momento, toda la vida del pueblo se vuelca en torno al carnaval, festejando.

La música del carnaval es también la de una territorialidad, conlleva un sentimiento de pertenencia al lugar y a la vida de su naturaleza. Con la música en primer orden del ritual, los hombres parecen acordarse y armonizar con los fenómenos naturales (estación de lluvia) y las cosechas del maíz, considerado como el fruto de la interacción entre los hombres y la naturaleza. De este modo se puede decir que el carnaval es revelador de una ontología: expresa «una serie de códigos de valores y de concepciones del mundo» (Losada 2005: 54), donde la pachamama es el centro de un «sistema de significación» (Mennelli 2007: 48).

7 La copla es un género musical muy estudiado (v.gr. Aretz 1952; Carrizo 1935; Vega 1944). Así, en su Cancionero popular de Jujuy, Carrizo determina la influencia española y la prehispánica. Aunque tengan formas legadas por la colonización (se cantan en español, se estructuran en cuarteto octosilábicos) los coplas son consideradas como cantos tradicionales de la zona andina del norte argentino (canto tritónico). En el carnaval, los copleros y copleras improvisan coplas a contrapunto. 
El sentimiento cultural y territorial es lo suficientemente potente como para que el carnaval convalide nuestra hipótesis de una relación dinámica entre arraigamiento y circulación: convoca a un número considerable de gente, «cada año miles de personas, incluyendo los originarios de la región que han emigrado y vuelven para esta fiesta, $\mathrm{y}$ un número importante de turistas que va aumentando cada año y más rápido aún desde la declaración como patrimonio mundial» (Losada 2005: 49).

\subsection{La peregrinación de Tilcara al abra de Punta Corral}

Cada año, el lunes de la Semana Santa, grupos de sikuris $^{8}$, tocando a la forma andina tradicional, «en contestado» y con tambores, hacen una peregrinación a la Virgen de Copacabana en un verdadero ritual extremadamente organizado en el espacio y donde la dimensión musical es absolutamente central. La territorialización es evidente y siempre realizada por la práctica musical: todas las bandas de sikuris tienen un lugar de ensayo; se juntan primero en la plaza de la iglesia de Tilcara, donde entran tocando para recibir la bendición del cura. Esta etapa, que se desarrolla por la tarde, es el punto de partida obligatorio de una caminata por una quebrada secundaria (el río Huasamayo); se empieza tocando y así se recorren sus $27 \mathrm{~km}$ superando un desnivel ascendente de 1.500 metros. La caminata se hace en una noche de luna llena, (o casi según el calendario) hasta el abra de Punta Corral, a $4.000 \mathrm{~m}$ de altura, donde se erige una capilla. Una multitud de gentes, bandas de sikuris y otros peregrinos o visitantes, van llegando poco a poco a lo largo de la noche. Todo el día del martes, los sikus y tambores resuenan en lo alto de la montaña desolada, creando una atmósfera propia de rituales a través de la música instrumental. Alrededor de la capilla se construye un cuadrado de pequeñas habitaciones donde duermen los músicos mientras los otros peregrinos cubren el suelo con multitud de tiendas (Figura 2). En la madrugada del miércoles empieza el largo descenso de las bandas que se turnan para llevar la Virgen hasta Tilcara. Al atardecer, los peregrinos entran en el pueblo siendo recibidos por una serie de altares de arcos floridos confeccionados para la ocasión y constituyendo las etapas del camino para volver a la iglesia de Tilcara. Participan familias enteras, niños y ancianos incluidos, procedentes de toda la Quebrada y viajeros venidos de provincias, a veces lejanas, que pueden integrarse en las bandas de músicos. C. Argañaraz evoca la duración de esta peregrinación -se estima que la primera capilla del abra de Punta Corral data de 1889- y destaca el sincretismo realizado entre la Virgen católica y el principio femenino de Madre, que se asocia en los Andes a la noción de Madre-Tierra. Para este autor, la procesión de los sikuris «determina un espacio sagrado», «un lugar de memoria incluyendo el sitio del altar, como también todo el largo camino que recorre las vertientes, sube y baja en la montaña, atraviesa el lecho de un río, las calles del pueblo... todo eso 'para la virgencita... la mamacita' (palabras de una lugareña)» (Argañaraz 2005: 86).

8 Son sikuris quienes tocan el siku, flauta andina autóctona de origen prehispánico. 


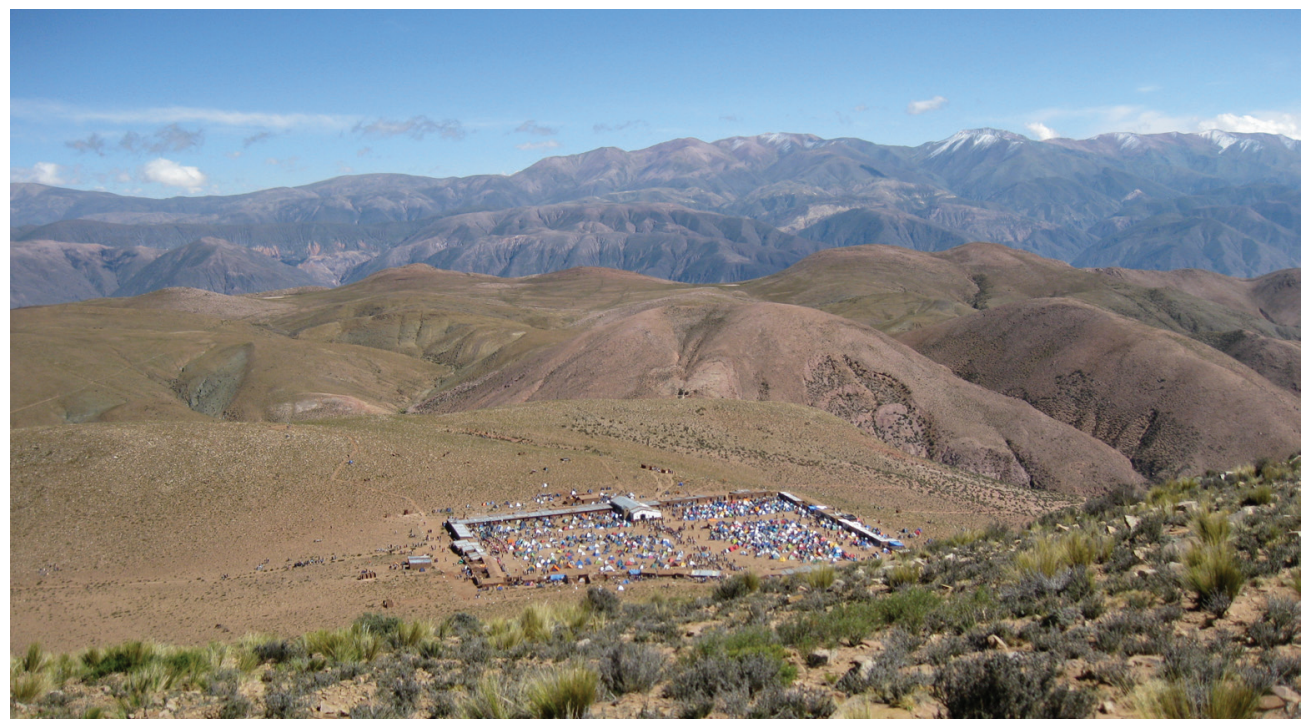

Figura 2: Vista general del santuario del Abra de Punta Corral durante la peregrinación de 2010.

\subsection{El mes de la Pachamama}

Ofrendas, señalada (marcada y casamiento de los animales) y challada (incensar las casas y los objetos de la vida cotidiana para limpiar el ámbito y ahuyentar los «malos espíritus») son otras prácticas locales donde la música y la naturaleza se asocian. En el otro extremo del año, en pleno invierno del hemisferio sur, el mes de agosto es el del descanso de la tierra (actividad agrícola), el tiempo de la renovación de sus fuerzas. El $1^{\circ}$ de Agosto, temprano al amanecer, los pueblos de la Quebrada, pero también de otras partes de NOA (p. ej. valles Calchaquíes de Tucumán y Salta) emanan un olor a incienso y se crea una atmósfera particular: en todas las casas se queman hojas de koa y laurel para incensar (sahumar), práctica que se considera una forma de limpieza y purificación. El mundo de los hombres se ajusta al ritmo de la naturaleza: a lo largo de todo el mes de agosto se deben respetar los recursos de la tierra, no quitarle mucho (p. ej. no cazar) y, por el contrario, darle ritualmente «de comer y de beber». La costumbre es que durante este mes cada casa invite a sus familiares y amigos para compartir la ofrenda. En algún lado de cada casa hay un agujero en la tierra que simboliza una entraña que se abre una sola vez durante el mes de agosto para que cada invitado haga su ofrenda: cada uno en su turno se arrodilla frente al agujero para echarle agua, chicha o vino, aguardiente, hojas de coca, semillas de maíz, cigarrillo y papel picado. También se le «da de comer»unas cucharadas de una comida preparada especialmente para la ocasión, para la tierra, con los mejores ingredientes y con gran cariño. Es un momento en el cual cada uno agradece a la tierra por sus «servicios», por dar la vida continuamente, manifestando así una relación de reciprocidad. 
Esta práctica no posee formas musicales tan propias como las del carnaval o las de la peregrinación de Punta Corral, pero en general la música acompaña la fiesta y muchas son las canciones que hablan de la pachamama con las mismas representaciones.

\section{Análisis referencial de letras de canciones: una conciencia geográfica}

Mas allá de las fiestas, la música folclórica se toca también en ocasiones más cotidianas, durante las guitarreadas entre amigos o en los conciertos y peñas organizados cada día en los restaurantes de Tilcara. En estas ocasiones se encuentran músicos (nativos o gringos) y público, frecuentemente personajes que conocen bien el folclore; «se toca o baila algo». Si tal es el caso, todos pueden ser invitados a participar, aunque sea canturreando, y así se realiza la función del compartir popular de estas tradiciones.

Inspirados en parte por investigaciones que tratan de las imágenes contenidas en el actual folclore del NOA (Furmanski 2003; Perassi 2007) y de las categorías conceptuales del mundo andino (Fischer 2008; Robin 2008; Sauvé et al. 2005) analizaremos aquí, desde una perspectiva geográfica, una muestra del repertorio tocado en estas prácticas cotidianas para averiguar si las canciones se presentan efectivamente como una traducción (sensu Berque 2007) de las relaciones con el medio y del sentido atribuido a la relación hombre/tierra. Explicaremos la selección del repertorio, propondremos un cuadro de análisis temático y lexical, y analizaremos los resultados obtenidos.

\subsection{Selección del repertorio}

Aunque nuestro estudio de terreno se enfoque en la Quebrada de Humahuaca, el repertorio estudiado pertenece a todo el folclore del NOA, definido por una dinámica de arraigamiento y circulación. Hemos seleccionado para el análisis una muestra de quince canciones que se interpretan una y otra vez en la Quebrada (Cuadro 1). La selección es difícil de hacer, pues hay una cantidad infinita de canciones interpretadas que podrían servir para el análisis; hemos basado nuestra selección en los siguientes criterios: el hecho de que estén realmente interpretadas en la Quebrada de Humahuaca, la presencia de ritmos folclóricos variados ${ }^{9}$ y la presencia no sólo de composiciones conocidas del repertorio popular sino también de canciones «inéditas» compuestas por músicos que viven en la Quebrada, impregnados de su cultura, pero que no son originarios de allí. Dentro de las quince canciones, nueve son ritmos diferentes del repertorio más conocido del NOA, dos son originarias de otros países

\footnotetext{
9 No tenemos aquí el espacio suficiente para presentar los diferentes ritmos folclóricos del NOA, algo que, sin embargo, convendría poder hacer en tanto que ello ilustraría, por sí mismo y en función de sus características musicológicas y de su historia, el encuentro entre lo prehispánico y lo hispánico, así como diferentes matices del vínculo con la tierra (p. ej. No es lo mismo una chacarera bailada en el tierral de los valles secos o una baguala cantada en el cerro).
} 
andinos limítrofes, y cuatro son composiciones actuales de los músicos «gringos» del pueblo de Tilcara.

Cuadro 1: Presentación del repertorio seleccionado

\begin{tabular}{|c|c|c|c|c|}
\hline & Nombre & Autor/composit. & Ritmo & Procedencia \\
\hline \multirow{9}{*}{$\begin{array}{l}\text { Cancionero } \\
\text { Popular } \\
\text { del NOA }\end{array}$} & $\begin{array}{l}\text { 1-Caminito del } \\
\text { Indio }\end{array}$ & A.Yupanqui & Baguala & $\begin{array}{l}\text { folclore de proyección } \\
\text { andina }\end{array}$ \\
\hline & 2-Balderrama & $\begin{array}{l}\text { Cuchi Leguizamon } \\
\text { \& J.M. Castilla }\end{array}$ & Zamba & Salta \\
\hline & 3-Doña Ubenza & Chaco Echenique & Hyano/baguala & Salta \\
\hline & 4-La viajerita & A. Yupanqui & Zamba carpera & $\begin{array}{l}\text { folclore de proyección } \\
\text { andina }\end{array}$ \\
\hline & $\begin{array}{l}\text { 5-Nostalgias de } \\
\text { Tucumán }\end{array}$ & Los Chalchaleros & Cueca & Tucumán \\
\hline & 6-El seclanteño & A. Petrocelli & Vidala & Salta \\
\hline & $\begin{array}{l}\text { 7-Chacarera del } \\
\text { Atardecer }\end{array}$ & Hnos. Simon & Chacarera & Santiago del Estero \\
\hline & 8-Guanuqueando & R. Vilca & canción & Qu. de Humahuaca \\
\hline & 9-Soy de la Puna & Colla Mercado & $\begin{array}{l}\text { Hyuano/ } \\
\text { carnavalito }\end{array}$ & Qu. de Humahuaca \\
\hline \multirow{2}{*}{$\begin{array}{l}\text { Folclore andino } \\
\text { (fuera del NOA) }\end{array}$} & 10-La Vicuñita & Anónimo popular & Huyano & Perú \\
\hline & 11-Mamita & Kala Marca & Tobas & Bolivia \\
\hline \multirow{4}{*}{$\begin{array}{l}\text { Composiciones } \\
\text { "inéditas" } \\
\text { actuales }\end{array}$} & $\begin{array}{l}\text { 12-Amigo Cam- } \\
\text { pesino }\end{array}$ & A. Scotto & Carnavalito & $\begin{array}{l}\text { folclore de proyección } \\
\text { Qu. de H. }\end{array}$ \\
\hline & $\begin{array}{l}\text { 13-Para la Que- } \\
\text { brada }\end{array}$ & A. Scotto & Chacarera & $\begin{array}{l}\text { folclore de proyección } \\
\text { Qu. de H. }\end{array}$ \\
\hline & $\begin{array}{l}\text { 14-Sangre de } \\
\text { cóndor }\end{array}$ & G. Costa & Huyano & $\begin{array}{l}\text { folclore de proyección/ } \\
\text { Qu. de H. }\end{array}$ \\
\hline & 15-De la Pacha & G. Sosa & $\begin{array}{l}\text { Milonga } \\
\text { campera }\end{array}$ & $\begin{array}{l}\text { folclore de proyección } \\
\text { Qu. de H. }\end{array}$ \\
\hline
\end{tabular}

\subsection{Cuadro de análisis}

Siguiendo las propuestas de Berque (2007), elaboramos un cuadro de análisis estructurado por las categorías léxicas y temáticas que constituyen para nosotros una evocación paisajística. A través de la letra de estas piezas, la música se manifiesta como la expresión inteligible y concreta de las percepciones, representaciones y prácticas de la tierra: una conciencia geográfica (Dardel 1952) y una geosofia (Wright 1947), constitutivas de una territorialidad, percepción sensible del paisaje y relación dinámica entre el topos (lugar cartografiable) y la chora (lugar en su dimensión percibida y vivida). Definimos así las categorías léxicas siguientes: 
- unidad paisajística: escala espacial.

- fenómeno y elemento natural: flora y fauna.

- contexto musical: referencia directa a la música como vínculo entre el hombre y la tierra.

- estados de alma, emociones y sentimientos relacionados con la tierra.

- la práctica de los lugares (trabajos rurales, instalaciones humanas inscritas en el paisaje, traslados).

- alusión al «indio».

El análisis lexical está hecho aquí de manera «artesanal» ${ }^{10}$, pero proporciona en principio unos resultados válidos. Las palabras y expresiones clasificadas en el cuadro no son de importancia secundaria en la canción sino que constituyen la temática misma. El análisis de los resultados de la clasificación lexical, a partir de nuestras categorías geográficas, permite entender, más allá de una aproximación cuantitativa, el contenido de la evocación paisajística que incluye un conocimiento del paisaje material (importancia de la observación) y una relación con el medio (por los usos del espacio, la sensibilidad al lugar y una forma de ética ambiental) que se expresa a menudo a través del mismo contexto musical. Lo que resalta primero en este análisis es la importancia que las canciones dan a todos los elementos del paisaje, mostrando así, a la manera de la geografía cultural, que el paisaje como medio de vida es el marco primordial e ineluctable de la experiencia humana. En palabras de Dardel (1952):

«Hay que entender la geografía no como el marco cerrado donde los hombres se dejan observar como insectos en un vivarium, sino como el medio por el cual el hombre realiza su existencia, en cuanto que la Tierra es una posibilidad existencial de su destino»

Así, este autor aboga por la necesidad de considerar una «geografía primitiva, interior» e integrar el estudio de una «conciencia geográfica», ya que «para el hombre la realidad geográfica consiste en el medio ambiente que le convoca a su presencia».

Esta dimensión de la vida humana, en relación indefectible con su medio ambiente, está asumida y expresada de forma inteligible a través de la clasificación siguiente, teniendo en cuenta que algunas expresiones o palabras pueden entrar a la vez en diferentes categorías por tener un mismo objeto varios aspectos geográficos. Procedamos entonces al análisis del repertorio escogido de acuerdo con categorías de análisis hasta aquí señaladas.

\subsubsection{Frecuencia de las referencias al espacio, según diferentes escalas y bajo diferentes aspectos}

- Sitios del NOA: Tucumán, Tafí, Cochuno, Alpachiri, Balderrama, Tolar.

- Grandes unidades de medios físicos y de territorio: tierra, puna, altiplano, cordillera, quebrada, América.

10 Queremos decir con ello que el análisis de clasificación ha sido realizado sin ayuda de programas informáticos, que sí deberían utilizarse para ampliar el repertorio de cara a una investigación mayor como pudiera ser una tesis doctoral. 
- La topografía, la red hidrográfica, los elementos de la Naturaleza: valle, montaña, cerro, arroyo, río, manantiales de agua, valle verde, piedra, arena, roca.

- Flora y fauna en el paisaje: ovejas, vicuña, cóndor, naranjos, «flor de amancay» (Hymenocallis amancaes), «flor de huancar» (Buganvilla), hoja de coca, arcos floridos.

- Elementos dinámicos del paisaje vivido y percibido con alusiones al clima y a la fenología (variación estacional y ritmo diurno/nocturno): viento, nube, lluvia, llover, valle verde, campo helado, floreciendo, noche, la oscuridad, primavera, invierno, la mañana, la tarde, alba, amanecer, atardecer, luz, «cerro azul».

Es de notar también que en la dinámica espacio-temporal de los paisajes se da importancia a la evocación no sólo de la tierra, sino también del cielo y de los astros: cielo, luna, sol, estrella.

\subsubsection{Alusión a la interrelación del hombre con el paisaje y el medio}

El hombre no se considera como un ser independiente y aislado; es uno de los varios elementos de un todo más grande que lo contiene y con el cual tiene varias interrelaciones:

- Producción agrícola y artesanal: sembrar, semilla, fruto, campesino trabajando la tierra, plantar, abonado de la tierra, desechos naturales, comida nueva, cerámica, «ponchito de lana».

- Desplazamientos, caminos, movimientos: de sur a norte, camino, sendero, viajerita, camina lento, «Baja una nube mientras él sube», «cruzando los montes vengo», distancia, viaje, «vengo de arriba», «del cerro yo vengo».

- Relación afectiva, emoción relativa al paisaje, a veces notable por los sufijos que indican una cierta familiaridad o intimidad: vicuñita, linda hojita de coca, lunita; llorando en el cerro, «se agranda en la noche la pena del indio», «canta por la noche, llora por la madrugada», «El viento va borrando huellas a mi dolor», «penas de arena», «que misterios tiene el monte en su soledad», frescor y aroma, «admirando tus ríos, tus mares, tus valles, tanta emoción».

Se podría objetar aquí que es muy común que el paisaje y la naturaleza sean fuentes de inspiración poética y que no se puede ver ahí una verdadera dimensión geográfica que trate de la relación del hombre con su medio. Pero si miramos la narrativa de la canción en su conjunto (Milliard 2010: documentos adjuntos), observaremos que se trata de un vínculo hasta metafísico, o al menos ético, porque expresa no sólo sentimientos, sino también valores y representaciones de la relación naturaleza/cultura. La evocación sensible del paisaje es aquí reveladora de una forma de ontología «india» donde los seres humanos comparten una relación de empatía con la tierra entendida como un todo, cuyo funcionamiento radica en millones de correspondencias entre todos los seres vivos (analogismo).

\subsubsection{Relación de empatía y lazo simbólico}

En esa percepción geográfica «india», el paisaje está vivo no sólo porque vive desde el punto de vista de la fisicalidad (Descola 2005), sino también porque es activo y 
ejerce una influencia directa, desde el punto de vista de la interioridad, sobre los estados del alma humana. Así podemos intuir que los estados de alma incluso se especializan y se hacen paisaje: «valles sonoros del pedregal, piedra por piedra el viento va, borrando huellas a mi dolor, silencio puro es mi corazón». No sólo se describe el paisaje físico, sino que se lo presenta como el contenedor de la vida humana, y así se establece, desde la fisicalidad y la interioridad, un continuum entre el paisaje y el hombre. En la cosmovisión perceptible a través de las músicas y sus letras, las redes de la vida son complejas y se asocian como vasos comunicantes. Así contestaba el cantautor Atahualpa Yupanqui a la pregunta «¿quién es el paisano?»: «es el que tiene el paisaje adentro» (cit. in Abdala 2007), acercándose así a esas ideas fundamentales de la geografía cultural de «lo primitivo», «lo interior». En este sentido, la respuesta se acerca a las ideas de Dardel (1952) acerca de que «hay que entender la geografía no como el marco cerrado donde los hombres se dejan observar como insectos en un vivario, sino como el medio por el cual el hombre realiza su existencia, en cuanto al que la Tierra es una posibilidad existencial de su destino», o al criterio de Frémont (1976) respecto de que «el espacio no es un simple objeto, ni el ojo que le observa una lentilla fría (...) también es obra y universo de signos. Modelado por los hombres, tanto sentido como observado, poema colectivo, tanto grabado sobre la tierra como red funcional de campos y caminos, evoca tanto y más de lo que es».

En las letras de las canciones estudiadas, esta relación se entiende a través de la evocación de la Pacha o Pachamama, que nombra la concepción de una tierra animada y dotada de sentimientos, hecha de ciclos, y donde el hombre es sólo un elemento más entre tantos. Lo que nosotros en este análisis hemos llamado tierra (asociación de territorio, territorialización y territorialidad, con medio ambiente, medio y paisaje), es así equivalente a la Pacha: una unidad espacio-temporal constituida por elementos naturales y culturales, físicos e interiores. Nuevamente, Atahualpa Yupanqui da una descripción cercana a la del geosistema de la geografía ambiental: todas la partes están en interrelaciones y correspondencia constantes, es «un sólo poncho», un tejido donde se entremezclan todos los seres vivos. Desde esta perspectiva se pueden enunciar las siguientes relaciones:

- Alusión a la cultura «india» y a su historia: diversas palabras en quechua (amacay, tata yaya, imillita chusca), «caminito del indio, camina de sur a norte mi raza vieja» ${ }^{11}$, pelo oscuro, trenzas negras, «mi raza vieja», poncho, acusi, sangre andina, «dulce carnaval»

- Relación de intimidad entre el hombre y su medio de vida, estableciendo un continuum hombre/paisaje: «soy de arriba, soy de Cochuna, ranchito, monte y río, soles y luna, palomita», «De arriba vengo, soy de la puna, carita y luna, flor de amancay», «del cerro yo vengo con mi vicuñita», «cara de roca, mastica coca» ${ }^{12}$.

- Importancia del camino desde un punto de vista simbólico: «sendero kolla sembrado de piedras, caminito del indio que junta el valle con las estrellas»; unos versos verosímiles desde un punto de vista topográfico, ya que el paisano andino camina muchísimo

11 La temática del camino es muy evocadora como práctica de territorialización y como mecanismo de conocimiento del medio. Como señala Abdala (2007: 114), «los kollas son un pueblo de caminantes. [...] El camino es la manera de unir la tierra con el cielo... Entre el espíritu y el cuerpo hay un cordón. El hombre no está sólo en el mundo».

12 La expresión no es en absoluto peyorativa, sino que se compara la cara del hombre andino con la roca por su tez morena y su piel arrugada por el sol y el clima seco de los andes. 
desde los fondos de los valles hasta los cerros o la puna. Pero también ponen en evidencia otra dimensión simbólica o metafísica: el hombre camina, vive materialmente sobre esta tierra, pero también su conciencia o su destino está vinculado con espacios misteriosos («que misterios tiene el monte en su soledad») y otros espacios cósmicos, «las estrellas».

- La Pacha: es un todo más grande que el hombre cuyo papel es unir, física, material y espiritualmente, los diferentes elementos de la tierra. Si se le consiente un sentimiento religioso («mamita estás rezando por la tierra»), es por el sentido de valor profundo atribuido a todas las formas de vida que hospeda, y de reconocimiento de los lazos de interrelaciones y reciprocidad: «para luchar contra esta vida dura, sólo te ayuda la linda hoja de coca, mamita linda tus ojeras son el orgullo de la pachamama... tu vientre y tu seno son arrugados, como la tierra que ha dado tanto fruto», "dale amor a la tierra, con buena semilla pura, la pacha te festeja».

\subsubsection{La música: expresión de una relación armónica entre el hombre y la tierra}

El análisis de las categorías lexicales también evidencia uno de los rasgos característicos de la cultura folclórica: el hecho de que la música, muy presente en lo cotidiano, parece actuar como un lazo entre la tierra y el hombre. Los folcloristas, antropólogos y/o músicos hablan de armonía y ritmos existiendo en el espacio y la naturaleza y con los cuales el hombre puede y debe acordarse: «la armonía se adquiere si uno escucha el mensaje del universo, y si uno camina en la vida al ritmo de la naturaleza y respetando sus ciclos» (Abdala 2007). Así se entiende que las evocaciones paisajísticas que hemos destacado en nuestro repertorio, no son fortuitas ni solamente descriptivas: son la expresión del paisaje para el hombre y en el hombre: se recomienda no olvidar que también «el hombre es naturaleza y si vibra con ella, ella le dicta las formas del canto» (Abdala 2007). Veamos como se observa en el repertorio seleccionado:

- La música, junto con el hombre, recorre el espacio, lo territorializa: «todos los del norte vienen trayendo señor cantos y alabanzas que son coplas de la tradición», «de arriba vengo poncho y vicuña, cantando coplas del carnaval», «desde los cerros, baja esta zambita, por eso la llamo yo la viajerita», «del cerro yo vengo...cantando y bailando», «te vas bailando en tu altiplano», «cantando en el cerro», «allá en el silencio que me dejen con esta canción».

- Acompaña los movimientos del paisaje y su percepción por el hombre: «canta en la media noche», «siento quenas que en el viento huyen», «el sol y la luna y este canto mío besaron tus piedras camino del indio»».

- La música «contiene»el medio; la naturaleza, la dimensión espacial y los paisajes mismos son musicales: «viene cantando la noche», «en mi quenita traigo el invierno», «valles sonoros del pedregal», «el valle verde lejos se pierde, como su canto», «con esta zambita trayendo de los cerros frescor y aromas», «esta tierra... parece entonar», «quenas que en el viento huyen».

- Conecta al hombre con el medio como parientes: es como si la música permitiera al hombre acercarse a la naturaleza, entrar en contacto con ella: «bailando en tu altiplano, como una estrella ${ }^{13} »$, «le doy ventajas a los vientos porque no puedo volar hasta que

13 Evocativamente hay que tener en cuenta que la presencia de las estrellas en la noche de los Andes es pasmosa, y que existe la sensación real de estar muy cerca al cielo. 
agarro mi caja y la empiezo a bagualear» ${ }^{14}$. El hombre se vuelve música al estar en contacto con el medio, se confunde con la música: «en la noche serrana llora la quena su honda nostalgia», "se levanta en el cerro la voz doliente de la baguala».

- Es la expresión privilegiada de la sensibilidad de las culturas andinas a la tierra: «zampoñas y quenas sonando, antiguo respiro en la boca, besos, besos de mi raza», «quien no cante en guitarreada con todo fervor se le hace nudo en la garganta, entierra el corazón».

\subsubsection{Composiciones «inéditas»: los «gringos» adoptan a la Pacha}

El interés de la selección de este repertorio es hacer figurar, junto con las canciones del NOA más populares y conocidas, aquellas composiciones actuales de músicos instalados en la Quebrada pero originarios de otro medio geográfico y sociocultural y en general urbano. Observamos que las letras que escriben, al igual que las otras canciones, validan nuestra hipótesis. La presencia del paisaje y de la relación sensible y afectiva con la tierra es explícita, pero notamos un aporte significativo: sus letras se sitúan en el contexto actual de crisis de todo tipo, incluso ambientales. Las canciones que hemos elegido aquí denuncian claramente las prácticas extremistas del naturalismo moderno. Así por ejemplo:

- Adopción de la Quebrada como proyecto de vida y comunicación musical con este lugar: «este suelo que he elegido parece entonar con la otra vida del hombre de simple mirar», «quebrada me has zamarreado todo quien fui ayer y aquí me encuentro cantando de puro placer».

- Elogio a la tierra, reconocimiento de lazos de parentesco y crítica de ciertos vínculos con la tierra por parte del mundo occidental moderno: «Manantiales de agua floreciendo en esta tierra, la que los hombres no quieren, no saben cuidar»; «Sólo soja hay en los campos que matan a la tierra, obligados de plantarla, hermano no te sometas, avancemos campesinos, dale amor a la tierra, con buena semilla pura, la pacha te festeja, con desechos naturales la pacha te festeja»; "Admirando tus ríos, tu mares, tu valles, tus montañas, tus lagos, tanta emoción, sólo los zurdos del alma y los ciegos del corazón no ven, te castigan, no sienten tu pena, sembrando de gris asfalto tu vida, tus verdes... y vos esperando que tiren semillas listas para darnos, a los que creemos en vos, a los que te pedimos perdón, cómo no voy a llorar, cómo no voy a gritar, bomba nuclear, minas abiertas, ah qué tristeza me da».

\section{Consideraciones finales}

El folclore del Noroeste Argentino entra en el marco de una dinámica geográfica de la temática naturaleza/cultura. A la par de la antropología de la naturaleza, esta dinámica invita a investigar los diferentes tipos de interacciones y correspondencias entre las sociedades humanas y el resto de seres vivos en un mismo entorno. Así, las prácticas musicales de la Quebrada de Humahuaca no sólo actúan en la territorialización del espacio, sino que también tienen la capacidad de expresar y traducir las

14 Bagualear es el acto de entonar el canto y ritmo folclórico llamado baguala. 
representaciones de la relación entre naturaleza y cultura: una evocación paisajística impregnada de las líneas conceptuales de una geografía andina.

Evidentemente, habría que tomar en cuenta muchas otras condiciones de producción de estas músicas, que por definición son híbridas y expuestas a muchas influencias extra-andinas: condiciones del mercado musical; ideología y mito-historia respecto al discurso postcolonial sobre «lo indio», la influencia de la Nueva canción latinoamericana de los años de 1970, etc. No se trata de fomentar una postura crédula e irreal de un indio andino puro y absolutamente sabio en su concepción de la relación entre Naturaleza y Cultura, pero al no creer tampoco en una actitud totalmente escéptica, nos parece que hay un potencial de investigación de las representaciones naturaleza/cultura en las prácticas musicales, aunque sean cruzadas entre legados histórico-musicales diferentes y condiciones de producciones ajenas a la sola cuestión de las representaciones locales. Esto es lo que quisimos ilustrar con este artículo, resultante -como dijimos- de una investigación más amplia (Milliard 2010). Lo interesante es que identificando la presencia de representaciones andinas de la relación hombre/tierra en las prácticas musicales, podemos abrir otra hipótesis respecto de la capacidad de estas músicas para hacer circular en la sociedad argentina no sólo una nueva conciencia territorial que integre todos sus patrimonios, sino también otra conciencia de la relación naturaleza/cultura desde la que alimentar las reflexiones de fondo sobre la organización del espacio y la gestión ambiental. ¿Cuál es, entonces, la cualidad de saberes que aportan las músicas folclóricas y su circulación socioterritorial a nivel nacional? Tratando de dar una respuesta plantearíamos una segunda hipótesis acerca de la transmisión de saberes sobre la tierra a través del folclore en circulación, una cuestión fundamental en nuestras actuales líneas de investigación de la educación relacionada con el medio ambiente y del papel de los patrimonios inmateriales.

\section{Referencias bibliográficas}

AbDala, Eliana E.

2007 La poesía de Atahualpa Yupanqui: '... guitarra dímelo tú'. Buenos Aires: Corregidor.

ARETZ, Isabel

1952 El folclore musical argentino. Buenos Aires: Ricordi Americana.

Argañaraz, Cristina

2005 «Peregrinación al Abra de Punta Corral: religión, poder e identidad». Revista de Investigación Folclórica 20: 81-90. Buenos Aires.

Berque, Augustin

2007 Le sauvage et l'artifice, les japonais devant la nature. Paris: Gallimard.

Bernand, Carmen

2007 «La culture comme vecteur de recomposition sociale», en L'Argentine, après la débâcle. Itinéraires d'une recomposition inédite, D. Quattrocchi-Woissson, dir., pp. 351-367. París: Observatoire de l'Argentine Contemporaine. 
Bruneau, Michel

2000 «Pierre Gourou (1900-1999). Géographie et civilisations». L'Homme 153: 7-26.

CArrizo, Juan Alfonso

1935 Cancionero popular de Jujuy. San Miguel de Tucumán: Universidad Nacional de Tucumán.

DARDEL, Eric

1952 L'homme et la terre. París: Editions du Comité des Travaux Historiques et Scientifiques.

Descola, Philippe

2005 Par-delà nature et culture. París: Gallimard.

2011 L'écologie des autres. L'anthropologie et la question de la nature. Versalles: Éditions Quae.

FISCHER, Eva

2008 «Comunidad andina, conceptos de territorialidad y procesos de transición». Société Suisse des Américanistes 68: 27-36.

FRÉMONT, Armand

1976 La région, espace vécu. París: Flammarion.

FURMANSKI, Natan

2003 «La imagen andina en la música folclórica popular argentina». Revista de Investigación Folclórica 18: 153-166. Buenos Aires.

Gudemos, Mónica

2008 «Espacio, sonido y ritmo astronómico en la concepción simbólica del Cusco incaico». Revista Española de Antropología Americana 38 (1): 115-138.

Guiu, Claire

2007 «Pratiques folkloriques dans les 'Terres de l'Èbre': représentations et mises en scène de la ruralité». Norois 204: 39-52. Rennes.

Leroux, Xavier

2007 «Pour une géographie de la musique traditionnelle dans le nord de la France». Bulletin de la Société Géographique de Liège 49: 59-65.

LÉZY, Emmanuel

2000 Guyane-Guyanes, une géographie»sauvage»de l'Orénoque à l'Amazone. París: Belin-Mappemonde.

LOSADA, Flora

2005 «Carnaval en la Quebrada de Humahuaca. Un espacio-tiempo para la concreción de identidades». Revista de Investigación Folclórica 20: 72-80. Buenos Aires.

MenNelli, Yamina

2007 «El contrapunto de coplas en el carnaval de cuadrillas Humahuaca. Una propuesta de estudio centrada en su performance». Revista de Investigación Folclórica 22: 48-63. Buenos Aires.

Milliard, Sarah

2010 Musiques populaires, environnement et paysage. Ancrage et circulation de savoirs sur la terre. Le cas du folk-lore du Nord-Ouest argentin ou la Pachamama à Buenos Aires. Tesis de Master. Université Toulouse-Le Mirail. Documento electró- 
nico, <http://w3.gep.univ-tlse2.fr/telechargement/promos/20092010/Milliard_Sarah_M2R.pdf>, con acceso el 20/12/2011.

Perasi, Lucas Andrés

2007 «Aproximación al folklore moderno jujeño: imágenes predominantes en las letras de sus canciones». Cuadernos de la Facultad de Humanidades y Ciencias Sociales 33: 127-142. San Salvador de Jujuy.

Plisson, Michel

1987 «Un genre musical du Nord-Ouest argentin: la baguala». Journal de la Société des Américanistes 73: 219-242.

RAIBAUD, Yves

2009 Comment la musique vient au territoire? Pessac: Maison des Sciences de l'Homme d'Aquitaine.

RoBIN, Valérie

2008 Miroirs de l'autre vie. Pratiques rituelles et discours sur les morts dans les Andes de Cuzco (Pérou). Nanterre: Société d'Ethnologie.

SALIN, Elodie

2009 «Les paysages culturels entre tourisme, valorisation patrimoniale et émergence de nouveaux territoires: la Quebrada de Humahuaca». Cahiers des Amériques Latines 54-55: 121-136.

Sauvé, Lucie, Hélène Godmaire, Marie Saint-Arnaud, Renée Brunelle y François Lathoud 2005 «Regards croisés sur une éducation relative à l'environnement en milieu autochtone». Recherches Amérindiennes au Québec 35 (3): 85-94.

Teruel, Ana A. y Marcelo Lagos

2006 Jujuy en la Historia: de la colonia al siglo XX. San Salvador de Jujuy: Editorial de la Universidad Nacional de Jujuy.

VEGA, Carlos

1944 Panorama de la música popular argentina. Buenos Aires: Losada.

Wright, John K.

1947 «Terrae Incognitae: The Place of Imagination». Annals of the Association of American Geographers 37: 1-15. 